\title{
MOBILIDADE HUMANA E TRABALHO: O CASO DE BRASILEIROS EM LETHEM NA GUIANA INGLESA
}

\author{
HUMAN MOBILITY AND WORK: THE CASE OF BRAZILIANS IN LETHEM IN ENGLISH \\ GUIANA
}

\author{
Júlia Maria Corrêa Almeida* \\ Eduardo Gomes da Silva Filho**
}

\begin{abstract}
Resumo: O presente artigo visa compreender o caso da mobilidade humana a partir do viés das migrações, relações transfronteiriças e de atividades laborais de brasileiros na cidade de Lethem na Guiana Inglesa. O estudo foi realizado a fim de investigar a busca de trabalho que transcorre na fronteira do Brasil com a República Cooperativista da Guiana, a partir da cidade brasileira de Bonfim, em Roraima, com a cidade de Lethem, na Guiana. Nesse contexto, pretendemos demonstrar a partir de dados obtidos em pesquisa de campo como caracteriza a ocorrência da mobilidade humana e a ordenação do universo do trabalho no contexto da globalização da economia, dispondo conceitos capazes de dar atenção à complexidade desse fenômeno migratório que ocorre nessa transfronteira, enfatizando as relações cotidianas da população dessa região, por meio do enlaçamento dessas comunidades translocais, bem como das transformações que ocorrem nesse espaço e que tem proporcionado mudanças de natureza econômica, cultural, política e social para os migrantes fronteiriços.
\end{abstract}

Palavras-chave: Mobilidade; Trabalho; Guiana Inglesa.

Abstract: This article aims to understand the case of human mobility from the bias of migrations, crossborder relation sand labor activities of Brazilians in the city of Lethem in English Guiana. The study was conducted in order to investigate the search for work that takes place on the Brazilian border with the Cooperative Republic of Guyana, from the Brazilian city of Bonfim, Roraima, with the city of Lethem, Guyana. We intend to demonstrate from data obtained in field search how it characterizes the occurrence of human mobility and the ordering of the universe of work in the context of economic globalization. This study also aims to show the complexity of this migratory phenomenonth at occurs in a transboundary ground, emphasizing the intertwining of these trans local communities, as well as the transformations that occur in this space and that has provided changes of economic, cultural, political land social nature for migrants.

Keywords: Mobility; Job; English Guyana.

O processo de mobilidade humana não é um fenômeno novo na história da humanidade. No entanto, nos últimos anos tornou-se assunto de relevância e ganhou uma nova dinâmica em função das grandes transformações tecnológicas presentes no contexto da globalização econômica. Portanto, o fenômeno da migração vem assumindo características distintas e apresentando mudanças em relação ao perfil dos migrantes e dos fluxos migratórios.

\footnotetext{
* Professora da Universidade Federal de Roraima, lotado no Campus Murupu. Mestre em Sociedade e Fronteira pelo Programa de Pós-Graduação em Sociedade e Fronteira-PPGSOF/UFRR.

* * Professor da Universidade Federal de Roraima, lotado no Campus Murupu. Mestre em História Social pelo Programa de Pós-Graduação em História-PPGH/UFAM.
} 
Desse modo, as cidades de Bonfim, no Brasil, e Lethem, na República Cooperativista da Guiana ${ }^{1}$, apresentam como limite geográfico natural o rio Tacutu ${ }^{2}$. Essa divisa, presente entre as duas cidades, foi transposta com a abertura da ponte binacional "Prefeito Olavo Brasil Filho"3, no ano de 2009, e possui uma extensão de 230 metros. A ponte é a primeira ligação terrestre entre os países e constitui um marco simbólico de aproximação bilateral, possibilitando atender às necessidades de tráfego e intercâmbio econômico e laboral entre os dois países, conforme observamos na figura 1 , a seguir.

Figura 1 - Imagem da ponte binacional Prefeito Olavo Brasil Filho sobre o rio Tacutu, que cruza 0 rio ligando a cidade brasileira de Bonfim, em Roraima, à cidade de Lethem, na Guiana.

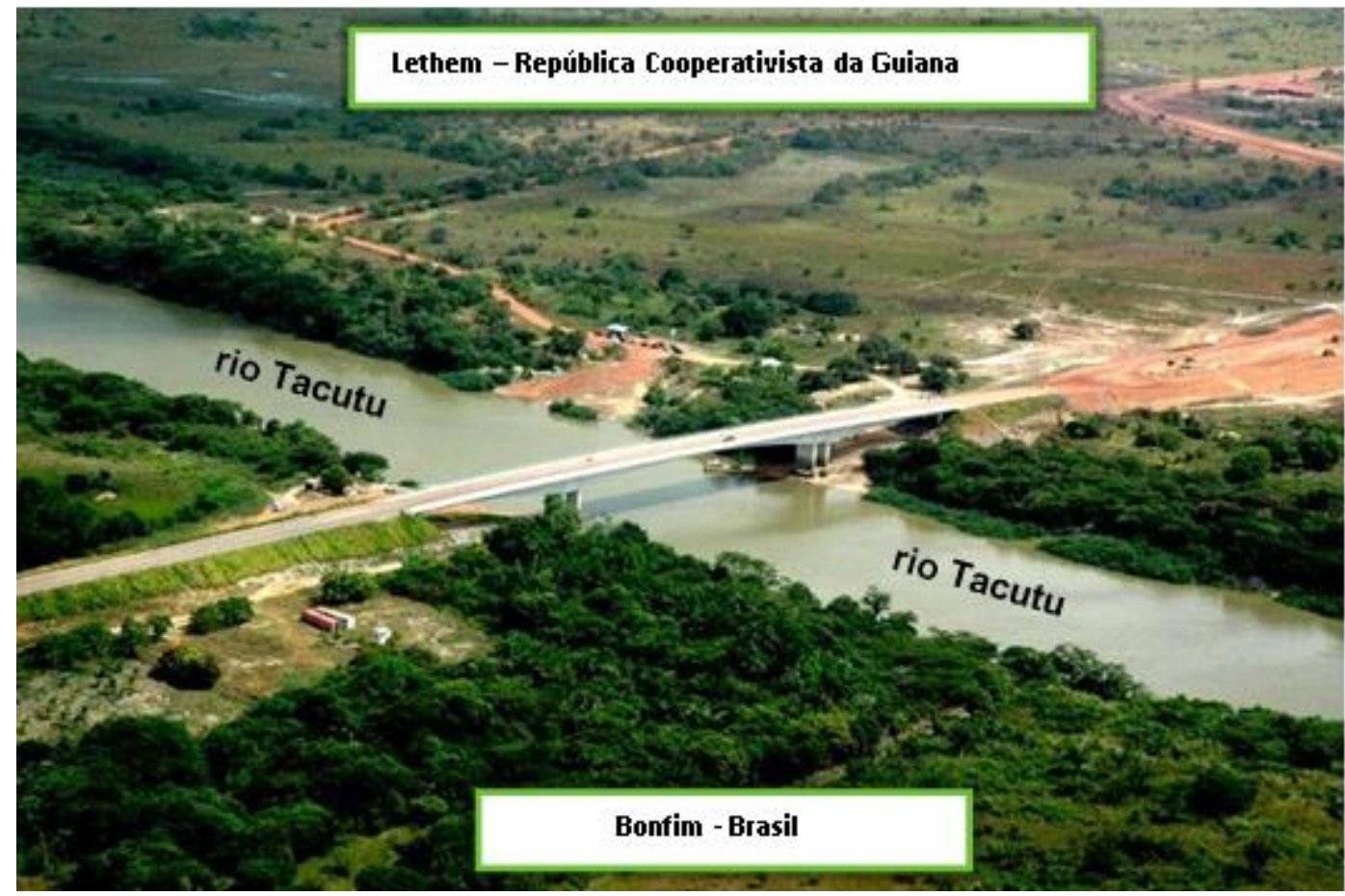

Fonte: Adaptado de SkyscraperCity, 2005.

A fronteira, objeto deste estudo, encontra-se no Estado de Roraima, que é uma unidade da federação brasileira localizada na porção mais setentrional do Brasil, com uma extensão territorial de 224.301,080 $\mathrm{km}^{2}$, que corresponde a 2,6\% da superfície do Brasil, estando a maior parte de seu território acima da linha do Equador. Roraima limita-se ao Norte com a Venezuela

\footnotetext{
${ }^{1}$ No que diz respeito a essa nomenclatura, também nos reportaremos a este país como Guiana, que significa "terra de muitas águas". De acordo com Corbin (2009), após seu processo de independência em 1966, passou a ser denominada de República Cooperativista da Guiana.

${ }^{2} \mathrm{O}$ rio Tacutu é um importante recurso natural, tem sua nascente na Serra de Acari, na fronteira da Guiana e seus principais afluentes pelo lado brasileiro são os rios Jacamim, Arraia e Urubu.

${ }^{3}$ A Lei No 11.918, de 09/04/2009, denomina a ponte binacional transposta sobre o rio Tacutu de Prefeito Olavo Brasil Filho, na BR 401, no Município de Bonfim, Estado de Roraima, divisa do Brasil com a República Cooperativista da Guiana, Publicado no DOU de 13/04/2009.
}

CANOA DO TEMPO - Mobilidade Humana e Trabalho: A situação de brasileiros em Lethem na Guiana 
e a Guiana, ao Leste com a Guiana e o Pará, e à Oeste com o Amazonas e a Venezuela, e ao Sul com o Amazonas.

Roraima pertence à Região Norte do Brasil, composta pelos Estados do Acre, Amazonas, Amapá, Pará, Rondônia, Roraima e Tocantins, e está dividido politicamente em 15 municípios: Boa Vista, Mucajaí, Caracaraí, Rorainópolis, São João da Baliza, Caroebe, São Luiz do Anauá, Bonfim, Normandia, Alto Alegre, Amajari, Pacaraima, Cantá, Iracema e Uiramutã.

A cidade de Bonfim, região fronteiriça analisada, localiza-se na porção Nordeste do Estado de Roraima, limitando-se ao Norte com Normandia, ao Sul com Caracaraí, a Leste com a República Cooperativista da Guiana e a Oeste com o município de Boa Vista e Cantá. Em se tratando da migração laboral, o processo de sobrevivência dos moradores da fronteira envolve a busca incessante de obtenção de renda para a manutenção e ascensão dos indivíduos e seus membros familiares.

Dessa forma, acreditamos que é a procura por emprego o principal impulsionador dessas mobilidades de trabalhadores brasileiros para Lethem, na República Cooperativista da Guiana, que buscam oportunidades empregatícias no país vizinho, permitindo, assim, a manutenção de famílias em Bonfim no Brasil.

Bonfim (RR) e Lethem (GY) representam espaços em que ocorrem deslocamentos de curta distância e, nesse contexto, essa pequena distância entre os países leva a um aumento da circularidade populacional nessa área fronteiriça, tendo em vista que as relações entre Brasil e Guiana se tornaram cada vez mais próximas, à medida que o governo brasileiro viabilizou o acesso terrestre com o país vizinho com a conclusão da ponte sobre o rio Tacutu.

Esse fluxo, no caso específico da fronteira Brasil-Guiana, é motivado por redes de comércio e serviço. Desse modo, essa mobilidade populacional na fronteira se origina das redes sociais e das relações de parentesco que tem lugar nesta área de fronteira. Elas são fortalecidas e consolidadas por meio das relações sociais realizadas continuamente neste espaço transfronteiriço.

Para o antropólogo Stephen Baines ${ }^{4}$, essas duas fronteiras coexistem e nela os povos indígenas Macuxi e Wapichana possuem uma história de colonização e contatos contínuos com os regionais das duas nações por mais de dois séculos. Existe um contingente populacional de etnias diferentes, que pode ser observado em ambos os lados da fronteira, provenientes de

\footnotetext{
${ }^{4}$ BAINES, Stephen G. A fronteira Guiana - Brasil e etnicidade entre povos indígenas. Revista Brasil do Caribe, Goiânia, v. VII, n.13, p.197-210, jul. 2006. 
processos migratórios ou indígenas, compondo uma complexa composição sociocultural nesse espaço.

Todas as relações étnicas e interétnicas incidem sobre a diversidade cultural da fronteira. Tudo se constitui em função daquilo que cada grupo de indivíduos acumula e partilha e que podem ser mensuradas por meio de suas memórias, conquistas e seus saberes. Com isso, essas redes que conectam as pessoas são capazes de criar um território em constante movimento. Desse modo, a fronteira se estabelece como um lugar de constantes trocas. Esse espaço oportuniza a compreensão de como essas sociedades se compõem, se formam e se organizam.

As experiências e conhecimentos adquiridos em função dos contatos nessa área de fronteira são motivados pelas relações de trabalho, etnia, parentesco, lazer, relações de comércio, enfim, em função das situações praticadas no processo de mobilidade populacional para trabalho, mas que por outro lado, fomenta práticas capitalistas. ${ }^{5}$

Vale destacar que não há consenso entre autores com relação à utilização de um termo comum, ao se reportarem ao processo migratório. Desta forma, optamos então por mencionar os termos "movimento", “mobilidade" ou "deslocamento" para designar o 'vai e vem', ou seja, a dinâmica populacional internacional diária, o trânsito para outra localidade, podendo implicar ou não na transferência temporária ou definitiva de residência.

Para Rosana Baeninger "não é possível traçar uma fronteira clara entre o que é uma mobilidade temporária do que é uma migração, e por isso a recomendação é compreendê-las de forma simultânea". 6

\section{MIGRAÇÃO TRANSFRONTEIRIÇA}

A migração internacional compõe a história da América Latina, dentro desse panorama a migração incorpora valor histórico, pois os movimentos populacionais foram marcantes para o avanço das áreas de fronteiras latinas, inclusive no Brasil, mais precisamente na Região Amazônica. Nos estudos sobre a migração internacional na Amazônia Luís Aragón ${ }^{7}$ historiciza que a Amazônia brasileira apresentou um período de significativas migrações ocorridas especificamente no fim do século XIX e início do século XX, em consequência de várias transformações ocorridas, sendo elas de natureza socioeconômicas e demográficas, do

\footnotetext{
5 A esse respeito Cf. MÉSZÁROS, 2004.

${ }^{6}$ BAENINGER, Rosana. Notas acerca das migrações internacionais no século 21. In: BAENINGER, R. (Org.). Migração Internacional. Campinas: Núcleo de Estudos de População - Nepo/Unicamp, 2013, p. 28.

${ }^{7}$ ARAGÓN, Luís E. Aproximação ao estudo da migração internacional na Pan- Amazônia. In: ARAGÓN, L. E. (Org.). Migração Internacional na Pan-Amazônia. Belém: NAEA/UFPA, 2009. 
crescimento do capitalismo e, ainda, de políticas do Brasil com objetivo de incentivar a vinda de europeus para atender à demanda brasileira de mão de obra em função da libertação dos escravos, pois careciam de trabalhadores para agricultura e, nessa perspectiva, buscava-se construir uma "civilização" baseada nos moldes europeus.

Existe anuência entre estudiosos sobre o processo de transformações na intensidade das mobilidades no contexto internacional. No período conhecido como a era das grandes migrações, esses fluxos internacionais adquiriram um importante papel no cotidiano social, conforme constatam os trabalhos de Baeninger ${ }^{8}$, Jakob $^{9}$ e Aragón. ${ }^{10}$

Entendemos que essa mobilidade humana na Amazônia ocorreu, em parte, em função de políticas governamentais, com o objetivo de "integrar"11 a região e, desta forma, ocupar os espaços que eles chamaram de vazios demográficos, principalmente nas áreas de fronteira, para assegurar a soberania nacional - e esse fator foi determinante na intensificação dos fluxos migratórios. $^{12}$

Já no que se refere ao aumento das mobilidades humanas entre fronteiras internacionais, podemos inferir que "os países fronteiriços da Amazônia apresentam uma manutenção da importância da migração para aquela região, apontando para a possibilidade de um aumento da circularidade destes migrantes na região". ${ }^{13}$

O entrelaçamento das fronteiras na Amazônia é uma realidade, no entanto, não é possível falar de um lado sem referir necessariamente o outro. Nesse sentido, a teoria do entrelaçamento se ajusta bem para pensar determinadas fronteiras, um exemplo disso são as mobilidades humanas e a permanente circularidade dos povos das diversas etnias entrecortadas pelas fronteiras geopolíticas em toda a região fronteiriça.

\footnotetext{
${ }^{8}$ BAENINGER, Rosana. Notas acerca das migrações internacionais no século 21. In: BAENINGER, R. (Org.). Migração Internacional. Campinas: Núcleo de Estudos de População - Nepo/Unicamp, 2013.

${ }^{9}$ JAKOB, Alberto Augusto Eichman. A migração internacional na Amazônia Legal brasileira e na metrópole de São Paulo nos anos 2000. In: BAENINGER, R. (Org.). Migração Internacional. Campinas: Núcleo de Estudos de População - Nepo/Unicamp, 2013.

${ }^{10}$ ARAGÓN. Migração Internacional na Pan-Amazônia. Belém: NAEA/UFPA, 2009.

${ }^{11}$ Com a finalidade de assegurar a ocupação do espaço físico da Amazônia, os governos militares, através da Política de Integração Nacional, realizaram uma rápida ocupação das áreas consideradas vazias, que foram processadas de forma contínua e controlada pelo Estado brasileiro. Nesses espaços que chamaram de "vazios" desconsiderou-se, completamente, a presença das populações nativas da região, os indígenas, promovendo uma condição de invisibilidade a esse povo, ou seja, assegurando-se somente os direitos de um grupo, negando completamente a presença das populações indígenas da região.

${ }^{12}$ A esse respeito Cf. SILVA FILHO. A Amazônia e o plano de integração nacional: os projetos de expansão e o avanço do capital nas sociedades tradicionais. Tempo Amazônico, v. V.3, p. 136-152, 2017.

${ }^{13}$ JAKOB. Migração Internacional. Campinas: Núcleo de Estudos de População - Nepo/Unicamp, 2013, p. 144. 
Bertha Becker ${ }^{14}$ confirma que as fronteiras tornam as relações transfronteiriças em um tema prioritário, pois há de se reconhecer a importância das diversidades geográficas, socioeconômicas, políticas e culturais no grau de vulnerabilidade e permeabilidade dessas fronteiras amazônicas. A autora esclarece, também, que embora a fronteira seja um fator de integração, à medida em que é uma zona de interpenetração recíproca e de frequente manipulação de estruturas culturais e sociopolíticas, cada fronteira apresenta estruturas econômicas, sociais, culturais, demográficas e políticas particularizadas.

A respeito da interação entre as cidades de Bonfim e Lethem, Antônio Meneses afirma que:

Bonfim e Lethem são duas cidades que compartilham do isolamento do restante de seus respectivos países - uma ao norte do Brasil, no estado de Roraima, a outra do sul da Guiana. Com a inauguração da ponte em abril de 2009, foi transposta a última barreira entre as duas cidades. Bonfim, em Roraima, e Lethem, na Guiana, vivem um intercâmbio cultural que extrapola tratados internacionais. Para chegar a uma compreensão desta questão, há que se examinar a história desta região e os processos de construção de dois Estados nacionais sul-americanos: o Brasil, ex-colônia portuguesa independente desde 1822, e a República Cooperativista da Guiana, ex-colônia holandesa e, posteriormente, inglesa até sua independência, em 25 de maio de $1966 . .^{15}$

O que verificamos nesse cenário, é uma complexa partilha entre as duas cidades, criando, desta forma, uma multiplicidade de laços que os ligam ao país de origem em diferentes áreas, que transcendem as fronteiras nacionais e complexificam suas relações sociais, tanto com as sociedades de origem, quanto com as de destino.

A cidade de Lethem, da República Cooperativista da Guiana, com a qual Bonfim faz fronteira, está localizada na Região do Alto Essequibo, é a capital da Região 9 (Upper Essequibo - Upper Tacutu). A República Cooperativista da Guiana é o único país da América do Sul que foi colonizado pelos ingleses. Segundo Mariana Pereira ${ }^{16}$, a cultura desse país se assemelha mais às nações caribenhas que às sul-americanas. Sua maior produção, desde a época dos ingleses, tem sido o açúcar e o arroz, que teve uma produção predominante na área costeira.

\footnotetext{
${ }^{14}$ BECKER, Bertha K. Amazônia: Geopolítica na virada do III milênio. Rio de Janeiro: Garamond, 2007.

15 MENESES, Antonio Vaz de. Cultura de fronteira Brasil/Guiana: festas. Boa Vista, 2014. 150 f. Dissertação (Mestrado em Sociedade e Fronteiras) - Universidade Federal de Roraima - UFRR, 2014, p. 23.

16 PEREIRA, Mariana C. A ponte imaginária: o trânsito de etnias na fronteira Brasil- Guiana. 2005. Tese (Doutorado em Antropologia Social) - Centro de Pesquisa e Pós-Graduação em Estudos Comparados sobre América Latina e Caribe (CEPPAC), Universidade de Brasília, Brasília, 2005.
} 
Paulo Visentini ${ }^{17}$ esclarece que aproximadamente $90 \%$ da população da Guiana está concentrada na faixa litorânea, em função do modo de colonização utilizada pelos ingleses que, preferencialmente, estabeleceram colônias agrícolas nas proximidades dos rios. Nesses assentamentos agrícolas a produção está direcionada ao cultivo de produtos tropicais, exploração de madeira e de outros recursos naturais. Desde 1973 integra o CARICOM ${ }^{18}$, que atualmente tem sua sede em Georgetown, capital guianense.

Para Corbin ${ }^{19}$, esse país se caracteriza por ser um país de origem, de trânsito e de destino de migrantes de várias categorias e é o único país Anglo fônico da América do Sul. ${ }^{20}$ Ainda de acordo com este autor, a emigração da população qualificada da Guiana é considerada uma das mais elevadas do mundo, pois além da alta emigração para nações desenvolvidas, a Guiana demonstra importante mobilidade com os países limítrofes.

Simões ${ }^{21}$, informa que a infraestrutura da cidade de Lethem ainda é incipiente, pois a cidade não possui ruas pavimentadas, iluminação pública adequada, praças e rede de esgoto. Possui algumas escolas e um único hospital público, onde são poucos os serviços oferecidos. Mas em termos de oportunidade, atualmente a cidade tem se apresentado mais atrativa, principalmente para os brasileiros que buscam trabalho e realização de compras.

No entanto, quando comparado ao município de Bonfim, com relação à infraestrutura, esse apresenta uma estrutura mais apropriada, possuindo escolas públicas nas modalidades de educação Infantil, Ensino Fundamental e Médio, um hospital, algumas ruas pavimentadas, coleta de lixo, abastecimento de água, energia elétrica, comunicação, praças, ginásio de esporte, rede de esgoto e programas federais de política de assistência social destinada à população bonfinense. $^{22}$

\footnotetext{
${ }^{17}$ VISENTINI, Paulo Fagundes. Guiana e Suriname: uma outra América do Sul. Brasília. Fundação Alexandre Gusmão, 2007.

${ }^{18}$ O Mercado Comum e Comunidade do Caribe (CARICOM), foi oficialmente efetivado no dia 4 de julho de 1973 , como um bloco de cooperação econômica e política. Formado por países ex-colônias europeias, pois essa condição de ex-colônias restringia seu desenvolvimento. Atualmente é composto por: Antígua e Barbuda, Bahamas, Barbados, Belize, República Dominicana, Granada, Guiana, Haiti, Jamaica, Montserrat, Santa Lúcia, São Cristóvão e Névis, São Vicente e Grenadines, Suriname e Trinidad e Tobago. Em 1998, Cuba foi aceita no grupo como país observador. O objetivo do Caricom é basicamente o desenvolvimento dos países envolvidos no bloco, através da ampliação das relações econômicas, o fortalecimento da economia regional e o estreitamento das relações comerciais com países europeus.

${ }^{19}$ CORBIN, Hisakhana. Migração Internacional e desenvolvimento: O caso da Guiana. In: ARAGÓN, L. E. (Org.). Migração Internacional na Pan-Amazônia. Belém: NAEA/UFPA, 2009.

${ }^{20}$ Hoje coexistem grupos étnicos nacionais como africanos, asiáticos, indianos, portugueses e indígenas e, dentre esses grupos, a maior representatividade demográfica é composta por afro descentes e indianos.

${ }^{21}$ SIMÕES, Sulamita Oliveira. Dinâmicas das cidades-gêmeas da fronteira Guyana (Lethem) Brasil (Bonfim) e a questão aduaneira/tributária. 2014. 197f. Dissertação (Mestrado em Sociedade e Fronteiras) - Universidade Federal de Roraima, UFRR, Boa Vista, 2014.

${ }^{22}$ Sobre a fronteira brasileira, Oliveira e Bethônico (2013), reforçam que a consolidação do município de Bonfim apresenta fatores considerados determinantes no seu processo de instalação, sendo eles: a efetivação das chamadas 
De acordo com dados do censo do IBGE em 2010, o comércio do município é inconsistente e o serviço público é praticamente a única alternativa de emprego. ${ }^{23}$ Por outro lado, a agropecuária é uma atividade de destaque no município de Bonfim, indicando a importância na economia local, da produção de arroz, melancia, milho, mandioca e soja.

É possível também observar o entrelaçamento cultural entre Bonfim e Lethem por meio do intercâmbio linguístico e econômico. No comércio de Bonfim, a moeda da Guiana - o dólar guianense - é aceita regularmente, assim como na cidade vizinha, em Lethem, no comércio local circula também a moeda brasileira, o real.

$\mathrm{Na}$ fronteira Brasil/Guiana, a constituição da relação fronteiriça é favorecida pelo comércio e serviços. Em razão dos contatos estabelecidos nessa região, que são propiciados pelas interações interdependentes entre as cidades, existe uma articulação que proporciona experiências diversas, impactando nas vidas de grupos sociais e familiares, estabelecendo vínculos de diferentes ordens, desde relações de amizade até relações comerciais, de trabalho, dentre outras.

Os trabalhadores migrantes brasileiros veem em Lethem uma alternativa de emprego e renda, incentivada pela proximidade desse país, caracterizando, desta forma, um fator de impulsão para a mobilidade transfronteiriça que, nesse contexto, não implica em mudança de residência, pois para esses trabalhadores brasileiros residentes em Bonfim é mais conveniente residir no município, em função da estrutura existente, com relação à educação, moradia e saúde, dentre outras, do que se domiciliar na cidade vizinha.

\section{RELACÕES DE TRABALHO E MOBILIDADE HUMANA: QUESTÕES PARA PENSAR A FRONTEIRA BRASIL/GUIANA}

Nas primeiras décadas do século XXI, calcula-se segundo a ONU, que existe aproximadamente 200 milhões de migrantes em todo o planeta. Entre os principais fatores que impulsionam estes movimentos podemos destacar: a crise econômica mundial, o desenvolvimento das tecnologias de informação e comunicação, desastres naturais, guerras, além da busca por melhores condições de trabalho e renda.

\footnotetext{
fazendas reais para a prática da pecuária, a abertura de garimpos, a criação de colônias agrícolas, a instalação dos pelotões de fronteira e os assentamentos rurais. Conforme elucidam os autores, essas medidas foram imprescindíveis para a fundamentação do município de Bonfim.

${ }^{23}$ Os empregos existentes no município de Bonfim concentram-se na esfera municipal, estadual e federal, que são admitidos por meio de concursos públicos ou cargos comissionados, e o comércio, por ser incipiente, não consegue atender a demanda de trabalhadores locais. Cf. IBGE. Censo 2010. Disponível em: http://www.censo2010.ibge.gov.br. Acesso em 11 de março de 2018.
} 
Apesar disso, a inserção no mercado de trabalho enfrenta algumas dificuldades, o que torna esses trabalhadores migrantes ${ }^{24}$, suscetíveis à informalidade, à negação de direitos trabalhistas e à trabalhos parciais, precários e temporários. Segundo a Organização Internacional do Trabalho, em seus dados de 2014, o ritmo de crescimento da globalização ${ }^{25}$ econômica criou mais trabalhadores migrantes do que nunca. $\mathrm{O}$ desemprego e o aumento da pobreza levaram muitos migrantes oriundos de países em desenvolvimento a buscar oportunidade de trabalho em outro lugar.

Todavia, os países desenvolvidos têm aumentado sua demanda de trabalho, particularmente para o não qualificado. Como resultado, milhões de trabalhadores e suas famílias se deslocam para outros territórios em busca de melhores oportunidades de trabalho, emprego e renda. Vivenciamos um momento histórico repleto de mudanças que não se delimitam a partes específicas do mundo, mudanças que têm se originado em todas as regiões, na sociedade, na política, na economia, no espaço do trabalho e, ainda, nas tradições culturais em diferentes circunstâncias e escalas espaciais instauradas pela globalização da economia.

Nesses processos de significativas transformações, compreender a conjuntura da mobilidade humana laboral de brasileiros em direção a outras nações, destacando suas implicações e ocorrências, explicitando as possíveis adversidades econômicas, sociais e culturais dessa região, oportunizará a composição de novos entendimentos acerca da temática em questão.

Desse modo, destacam-se as alterações nas relações no mundo do trabalho e nas novas formas de produção, condicionadas por mutações no universo produtivo que buscam continuamente regular a concentração de capital ${ }^{26}$, valendo-se, dentre outros recursos, da

\footnotetext{
${ }^{24}$ Vichich (2015) e Sprandel (2007) asseveram que são denominados como "trabalhador migrante" aquelas pessoas que trabalham em um país que não é aquele em que nasceram, isto é, todo ser humano que realiza ou realizou uma atividade remunerada em outro país. De acordo a Organização Internacional do Trabalho (OIT), o termo trabalhador migrante indica toda pessoa que se desloca de uma nação para outra, com vista a desempenhar um trabalho que não seja independente. Em 1990, no decurso da Convenção Internacional sobre a Proteção dos Direitos dos Trabalhadores Migrantes e dos Membros das suas Famílias, desenvolveu-se uma definição mais ampla, por instrumento da Resolução 45/158 da Assembléia Geral da ONU.

${ }^{25}$ Nas últimas décadas do século XX, o termo "globalização" se tornou uma palavra muito utilizada, sendo adotada por pesquisadores políticos e econômicos, por consultores de empresa, por governantes, por sindicalistas, pela mídia em geral, como, também, na discussão acadêmica em torno da interpretação das transformações econômicas, sociais, políticas e culturais experimentadas em escala mundial. Para Gorender (1997), esse processo traduz uma nova nomenclatura, designando a técnica de internacionalização do mercado procedente do sistema capitalista. Em uma perspectiva mais atualizada, Costa $(2008$, p.27) assevera que "a globalização é um fenômeno do nosso tempo, uma singularidade originária do capitalismo que foi construído a partir da segunda metade do século 20 , momento em que as corporações iniciaram a aventura de internacionalização da produção".

${ }^{26}$ Para Karl Marx (2006, p. 46-53), o capital "é uma relação social de produção. É uma relação burguesa de produção, uma relação de produção da sociedade burguesa. [...] O capital não consiste no fato de o trabalho acumulado servir ao trabalho vivo como meio para nova produção. [...] Consiste no fato de o trabalho vivo servir ao trabalho acumulado como meio para manter e aumentar o seu valor de troca". Desta forma, para Marx, capital 
Divisão Internacional do Trabalho-DIT ${ }^{27}$, transformando mecanismos de precarização e de exploração da força de trabalho, promovendo uma desagregação estabelecida pelo modelo capitalista.

Para Helena Hirata ${ }^{28}$, a década de 1990 foi assinalada por significativas mudanças no contexto internacional, originando um crescente desenvolvimento da informalidade no mundo do trabalho, bem como da produção nos países do Norte e do $\mathrm{Sul}^{29}$, proporcionando o estabelecimento de um mercado mundial unificado, favorecendo novas possibilidades para o capitalismo e aguçando a diversidade das situações de trabalho, emprego e atividades entre homens e mulheres. Assim, a autora se apropria dos termos "inclusão e exclusão" para qualificar a estruturação das zonas desenvolvidas e das zonas excluídas do desenvolvimento. ${ }^{30}$

Nessa circunstância, as mudanças ocorridas particularmente nas duas últimas décadas do século XX incidiram de forma significativa nas relações laborativas, tanto no modo de admissão, como de rendimentos, tornando esses trabalhadores mais subordinados hierarquicamente, visto que essas medidas visam permanentemente controlar a concentração de capital, assegurando novas oportunidades de lucro e exploração. Por essa razão, François Chesnais enfatiza que:

significa um modo de produção social cuja relação de trabalho se define pela apropriação privada do excedente econômico que fora produzido pela classe do trabalho. Capital é, por isso, não somente o tipo de relação social burguesa, mas também a porção excedente em riqueza daquilo a que damos o nome de dinheiro, sendo este uma das formas de manifestação do capital. Nesse sentido, e como bem assinalou Marx (2006, p. 47), “[...] a condição primeira, necessária ao capital, é a existência de uma classe com capacidade de trabalho. Pressupõe-se então, que o capital está associado ao trabalho assalariado, e o trabalho assalariado, por conseguinte, ao capital. Assim sendo, um é condição do outro, e nessa interdependência, eles coexistem na circunstância de um originar o outro, de forma contínua, num ciclo infindável. [...] O capital não é apenas um montante de produtos materiais, mas a somatória de mercadorias, de valor de troca e grandezas sociais" cuja reprodução se estabelece a partir da exploração do trabalhador assalariado dentro do modo de produção capitalista.

${ }^{27}$ Segundo Pochmann (2006), o capitalismo nos dois últimos séculos instituiu uma recorrente desigualdade na Divisão Internacional do Trabalho (DIT). Nesse sentido, a produção e a capacidade de incorporar uma maior ou menor massa de trabalhadores não dependem tão somente da estratégia de crescimento, mas do grau de amadurecimento econômico alcançado por cada país. Assim sendo, a qualidade do trabalho será determinada pelo progresso tecnológico e pela ordenação do trabalho. Dessa forma, essa condição estabeleceu uma hierarquia econômica e política, reforçando a hegemonia econômica entre os países centrais e periféricos.

${ }^{28}$ HIRATA, Helena. Globalização e divisão sexual do trabalho. Cadernos Pagu, n.16- 17, p.139-156, 2001/02.

${ }^{29} \mathrm{Na}$ interpretação de Hirata (2001), os termos "Norte e Sul" referem-se à estruturação de zonas desenvolvidas e de zonas segregadas do processo de desenvolvimento, com relação à organização de um mercado mundial consubstanciado, aumentando a defasagem das situações de trabalho, emprego e renda. A regionalização NorteSul foi desenvolvida para designar a atual conjuntura socioeconômica internacional e sua utilização se torna mais adequada, pois não notabiliza as desigualdades desses países. Dentre os países que pertencem a essa divisão temos a Alemanha, Japão, França, Estados Unidos, Canadá, Reino Unido, dentre outros, bem como, com relação aos países do Sul, temos a China, Índia, Brasil, Colômbia, Rússia, Argentina, Venezuela, dentre outros.

${ }^{30}$ Para Costa Pinto (1978), o conceito de desenvolvimento está associado a uma das fases do modo de transformação social no mundo contemporâneo, referindo-se às modificações incorporadas em diferentes segmentos das sociedades determinadas como atrasadas, em relação ao modelo de evolução da "Revolução Industrial" na atualidade, objetivando, desse modo, modificar essa ordenação, com a finalidade de suplantar o atraso, em relação à sociedade internacional. 
O capital é constituído de concentrações de dinheiro (nas formas que este utiliza em um dado momento) cujo objetivo exclusivo é a autovalorização, a reprodução com um aumento, um lucro, um excedente, uma mais-valia. Esta autovalorização é sem fim: "o capital, como representação da forma geral da riqueza - o dinheiro - tem a tendência, desenfreada e ilimitada, de ultrapassar os seus próprios limites. Se não fosse, ele deixaria de ser capital, quer dizer: dinheiro que se produz a si mesmo". ${ }^{31}$

Outrossim, Karl Marx, ${ }^{32}$ discorre em Trabalho assalariado e capital e salário, preço e lucro que o trabalho é o princípio vital, atividade essencial por meio da qual os homens alteram a natureza de acordo com suas necessidades e, assim, transformam a si mesmos, continuamente. O trabalho é, assim, atividade de humanização.

Todavia, para Jean Paul Gaudemar o mundo capitalista transformou o "trabalho" em atividade assalariada e alienada. Dessa forma, a força do trabalho humano se torna uma mercadoria, onde sua finalidade se concentra, incessantemente, em elaborar novos produtos e valorizar o capital, pois:

A força de trabalho é então definida sem equívoco, como a mercadoria que um homem possui ou ainda o conjunto de faculdades psíquicas, físicas e intelectuais que existem no corpo de um homem, na sua personalidade viva, e que ele tem de pôr em movimento para produzir coisas úteis. Mercadoria que tem a virtude específica de transformar o dinheiro em capital. ${ }^{33}$

Em outras palavras, o trabalho humano se afigura como um artigo específico do trabalhador, compreendido como uma "mercadoria" imprescindível ao processamento da transformação do dinheiro em capital. Desse modo, o indivíduo na condição de trabalhador, necessita se submeter às circunstâncias do capitalismo, estabelecidas pela ordenação das atividades diárias, carga horária, regime contratual, e em contrapartida o trabalhador receberá uma remuneração.

O capitalismo, ao determinar o processo de dominação do homem, transforma o trabalho humano em uma atividade totalmente alienante em função da maneira como se aproveita dessa força humana, cujo objetivo é a maximização do lucro. Desse modo, esse trabalho deixa de ser concebido como uma atividade de realização para o trabalhador e passa a ser uma atividade esgotante e alheia.

${ }^{31}$ CHESNAIS, François. Mundialização do capital e jogo da lei da população inerente ao capitalismo. In: SOUSA, A. A.; ARRAIS NETO, E. A.; FELIZARDO, J. M. CARDOZO, M. J. P.; BEZERRA, T. S. A. M. (Orgs.). Trabalho, capital mundial e formação dos trabalhadores. Fortaleza: Editora Senac/Ceará; Edições UFC, 2008, p. 23.

${ }^{32}$ MARX, Karl. Trabalho assalariado e capital e salário, preço e lucro. $1^{\text {a }}$ Ed. São Paulo: Expressão Popular, 2006.

${ }^{33}$ GAUDEMAR, Jean-Paul. Mobilidade do trabalho e acumulação de capital. Lisboa: Estampa, 1977, p. 189. 
Assim, é nesse censo de aparente "normalidade" que se sustenta a exploração do trabalhador, pois o capitalismo gera novas estratégias de controle social, cujo preço é a subordinação, a alienação, a desumanização e o enfraquecimento do intelecto do ser humano, que sobrevém ao longo da realização de tarefas estressantes e repetitivas, comprometendo a capacidade mental do indivíduo. Nessa circunstância, Antonio David Cattani certifica que:

Para ser eficaz, a dominação precisa parecer legítima, precisa ser naturalizada pelos dominados. [...] a domesticação se forja não nas formas pretéritas de organização de trabalho, e sim a partir de novos condicionamentos. Os jovens ingressantes na esfera produtiva social confrontam-se com uma situação terrível: o desemprego e o trabalho precário apresentam-se como realidades objetivas; as ocupações produtivas autônomas ou assalariadas. [...] a impossibilidade de alcançar a autonomia leva-os a aceitar trabalhos precários, que favorece a dependência e a subalternidade. A vulnerabilidade assim estabelecida se traduz em falta de autonomia, em menoridade do indivíduo, que passa a carecer da proteção, da tutela, do favor condescendente de outrem. ${ }^{34}$

Esta configuração possibilita uma reflexão acerca do processo de "dominação" do trabalhador, ou seja, de como essa estratégia é absorvida como algo naturalizado no mundo do trabalho. Constantemente nos deparamos com o agravamento de trabalhos precários, a informalidade e o desemprego, que potencializam atribulações sociais não menos significativas, como a exclusão social, a fome, a criminalidade, as transgressões, enfim, a debilidade das condições de vida humana - questões que, em geral, também podem estar relacionadas aos processos de mobilidade humana.

Partindo de tal pressuposto, essas recentes disposições econômicas atualizam seus métodos de controle e de gestão do trabalho, instituindo um processo de exclusão do trabalhador que cada vez mais, em função da redução do trabalho assalariado, multiplica-se de maneira terrível, acumulando trabalhadores excedentes, ou seja, o exército de reserva de mão de obra.

Segundo Cardozo, "a acumulação capitalista produz constantemente, em proporção à sua intensidade e à sua expansão, uma população excedente, supérflua e desprovida de meios materiais e de meios de procurar trabalho". ${ }^{35}$ Desse modo, o estabelecimento dessa mão de obra em estoque, determinado pelo sistema econômico vigente, marginaliza esses trabalhadores que

\footnotetext{
${ }^{34}$ CATTANI, Antonio David. A vida precária: bases para a nova submissão. In: CATTANI, A. D.; DÍAZ, L. M (Orgs.). Desigualdades na América Latina: novas perspectivas analíticas. Traduzido por Ernani Ssó. Porto Alegre: Editora da UFRGS, 2005, p. 69.

${ }^{35}$ CARDOZO, Maria José Pires Barros. A produção flexível e a formação do trabalhador: o modelo da competência e o discurso da empregabilidade. In: SOUSA, A. A.; ARRAIS NETO, E. A.; FELIZARDO, J. M.; CARDOZO, M. J. P.; BEZERRA, T. S. A. M. (Orgs.). Trabalho, capital mundial e formação dos trabalhadores. Fortaleza: Senac/Ceará; Edições UFC, 2008, p. 173.
} 
são rejeitados pelo mercado de trabalho, ou seja, se propaga um sistema impiedoso, colocando esses trabalhadores migrantes em uma situação de exclusão social desmedida. Ao tratar desta questão, François Chesnais comenta:

O exército industrial de reserva obtém-se, com a ajuda de um processo bem simples [...], da aplicação de métodos que, deixando o trabalho mais produtivo, diminuem sua demanda. O que chamamos hoje de "novas tecnologias" representam, a partir desse ponto de vista, um processo muito importante para o capital. As tecnologias da informação e da comunicação (o computador, o satélite, etc.) permitem às empresas reduzir a demanda por trabalho (o montante da força de trabalho que elas devem comprar no "mercado de trabalho") e, também, transferi-la para países em que o custo da força de trabalho é, com produtividade mais igual, objetivamente mais barata. ${ }^{36}$

Presume-se, portanto, que para o sistema de produção capitalista assegurar esse recurso de acumulação funcionando é necessário que uma parcela da população ativa se mantenha continuamente desocupada, isto é, sem trabalho.

O capitalismo necessita manter um exército de reserva de mão de obra, pois é por meio desse artifício que consegue potencializar os mecanismos utilizados pelo sistema, visando cada vez mais dar permanência e aprofundamento às condições de desemprego, de exclusão social, de empregos temporários e da diminuição salarial desses trabalhadores.

Dessa forma, consegue assegurar as condições de submissão e de rebaixamento da jornada de trabalho, deteriorando as condições de trabalho e os direitos sociais desse contingente de trabalhadores.

Portanto, diminuir a oferta de trabalho e, ainda, assegurar uma reserva de mão de obra desempregada é, na realidade, uma estratégia para assegurar o desenvolvimento do capitalismo, desmontando as garantias trabalhistas e pressionando esses trabalhadores a se sujeitarem a essas circunstâncias. Assim, em função das mudanças ocasionadas pelo processo de mundialização econômica, de revolução tecnológica e da reorganização do mundo do trabalho, constituiu-se um exército industrial de reserva nunca imaginado em toda história do capitalismo moderno. Essas circunstâncias configuram um profundo quadro de discriminação no mundo do trabalho informal, com adoção de salários diminutos, incapazes de assegurar as necessidades primárias dos trabalhadores que são, com frequência, obrigados a aceitar trabalhos sem registro formal.

Nesse contexto, surge como alternativa para o trabalhador a busca de espaço para comercialização de sua força de trabalho. Essa é a viabilidade alcançada visando assegurar sua

${ }^{36}$ CHESNAIS, François. Trabalho, capital mundial e formação dos trabalhadores. Fortaleza: Editora Senac/Ceará; Edições UFC, 2008, p. 31.

CANOA DO TEMPO - Mobilidade Humana e Trabalho: A situação de brasileiros em Lethem na Guiana 
sobrevivência, ou seja, o único instrumento que lhe restou na sociedade para se preservar das inquietudes da economia global e seus corolários. Nesse entendimento, é imprescindível para o capitalismo assegurar essa condição de força de trabalho enquanto mercadoria. Assim, para Marx resta:

[...] ao operário, cuja única fonte de rendimentos é a venda de sua força de trabalho, não pode deixar toda a classe dos compradores, isto é, a classe dos capitalistas, sem renunciar à existência. Ele não pertence a este ou àquele capitalista, mas à classe dos capitalistas. ${ }^{37}$

Por meio dessas análises, entendemos que a mobilidade da força de trabalho humana se manifesta como condição substancial para o capitalismo. $\mathrm{O}$ trabalhador, visando assegurar sua sobrevivência, comercializa sua força de trabalho, segundo as especificações impostas pelo mercado de trabalho. Assim, essa mercadoria "trabalho humano" é determinada pela lei da oferta e da procura que, consequentemente, é estabelecida pelo mercado de trabalho como produto essencial.

O século XXI, evidencia um panorama repleto de imprecisão no mundo do trabalho, promovendo o surgimento de divergências, de espaço de inseguranças, de incertezas, de desempregos, de destituição dos direitos adquiridos e de empregos precários e terceirizados, aumentando o exército de desempregados espalhados pelo mundo, constatando as contradições que caracterizam o mundo do trabalho nesse século.

\section{ESPAÇOS LABORAIS E CONDIÇÕES DE TRABALHO DE BRASILEIROS NA TRANSFRONTEIRA BRASIL/GUIANA.}

Fatores como a pobreza, a dificuldade de subsistência humana e a falta de perspectivas, são alguns motivos que impulsionam a migração em busca de trabalho. Nesse sentido, a mobilidade humana laboral, em busca de obtenção de renda, pode contribuir para o aumento do poder aquisitivo, de renda e, de modo geral, melhorar a condição social e econômica das famílias. A escolha deste tema se reveste de especial importância, dadas as possíveis consequências sociais as quais são submetidas as famílias dos trabalhadores transfronteiriças, bem como as possíveis implicações desse processo nas unidades familiares.

Portanto, a realização de uma análise e uma reflexão mais atenta sobre o tema se configura como um desafio para o entendimento do processo de mobilidade laboral na fronteira,

\footnotetext{
${ }^{37}$ MARX, Karl. Trabalho assalariado e capital e salário, preço e lucro. $1^{\text {a }}$ Ed. São Paulo: Expressão Popular, 2006.

CANOA DO TEMPO - Mobilidade Humana e Trabalho: A situação de brasileiros em Lethem na Guiana 
ao mesmo tempo que alarga o diálogo sobre a questão, do ponto de vista acadêmico. Desse modo, urge a necessidade de analisar os impactos da mobilidade populacional laboral de brasileiros em Lethem/Guiana que, na busca pelo sustento e na ausência de emprego, obrigamse a ir até a cidade fronteiriça, mesmo que seja para postos de trabalhos precários, com jornada diária extensa.

Nessa direção, enfatizamos os processos de mobilidade laboral transfronteiriça, posto que nosso interesse visa compreender quais são as condicionantes desse processo de mobilidade humana laboral internacional na atualidade e como intercorre a inserção desses trabalhadores transmigrantes brasileiros no mercado de trabalho, em Lethem/Guiana, considerando a atual contextura econômica global, bem como as experiências que esses trabalhadores vivenciam ao se dirigirem a essa transfronteira para trabalhar.

O termo "fronteiriço é utilizado pela comunidade local ao se reportar aos trabalhadores transmigrantes, que realizam a travessia diária e contínua para o outro lado da fronteira, em busca de emprego, de salário e de remuneração, fatores imprescindíveis à sua sobrevivência e de sua família, retornando ao seu país de origem ao término de cada jornada de trabalho, ao fim de cada dia. Para Oliveira, essa realidade:

[...] configura uma formação social associada diretamente às relações transfronteiriças do uso desse território como um espaço comum de convivência entre as duas nações, por sujeitos que produzem a sua existência por meio das relações de trabalho e economia. ${ }^{38}$

A pouca qualificação e a falta de perspectiva em seu município de origem induzem os trabalhadores a avistar uma oportunidade de emprego na cidade vizinha, mesmo que temporária, e nesse sentido se aventuram nesse mercado de trabalho, realizando tarefas, muitas vezes, degradantes e exaustivas, cumprindo cargas horárias que ultrapassam às $10 \mathrm{~h}$ diárias de trabalho.

Dessa forma, objetivando substanciar o processo da mobilidade humana laboral nessa transfronteira, buscamos auxílio na afirmativa de Simões, esclarecendo que:

Atualmente, observa-se que o fluxo pendular na busca pela oportunidade de emprego surge com mais ênfase na cidade de Lethem, justamente, porque os brasileiros são atraídos pela oferta do crescente comércio local. São trabalhadores diaristas ou sazonais, sem qualificação ou semiqualificados, que trabalham em Lethem e, em sua maioria, vivem em Bonfim. Também, há a

38 OLIVEIRA, Márcia Maria de. Dinâmicas migratórias na Amazônia contemporânea. 2014. 340f. Tese (Doutorado em Sociedade e Cultura na Amazônia) - Universidade Federal do Amazonas, UFAM, Manaus, 2014, p. 68 .

CANOA DO TEMPO - Mobilidade Humana e Trabalho: A situação de brasileiros em Lethem na Guiana 
presença de trabalhadores que se encontram em situação ilegal, a depender da tolerância dos empregadores e das autoridades locais. ${ }^{39}$

Esse comentário desvela a existência de uma mobilidade humana laboral nessa transfronteira. Lethem, nos últimos anos, em decorrência das transformações econômicas, das obras de infraestrutura e da proximidade geográfica, se configura como um mercado favorável e, a princípio, receptivo para os trabalhadores migrantes bonfinenses, que cruzam essa fronteira na esperança de construir uma vida por meio de sua inserção no mercado de trabalho em Lethem, na Guiana.

Nesse seguimento, a fronteira entre o Brasil e a República Cooperativista da Guiana concentra migrantes brasileiros que se deslocam à procura de emprego, particularmente no lado guianense e, em especial, aqueles que residem no município brasileiro, Bonfim, legitimando uma dinâmica existente entre essas duas cidades, que em sua contextura regional subsistem preservando esse vínculo de dependência mútua, nessa fronteira.

Assim, quando examinamos Lethem na contextura de uma fronteira transnacional, dando ênfase à sua conjuntura comercial, verificamos o aumento da área comercial, particularmente no território guianense, que evidencia uma expansão no comércio e na urbanização local.

É possível se deslocar a pé em Lethem, por ser uma cidade pequena, pois a localização dos estabelecimentos comerciais, praticamente, concentra-se na avenida principal denominada Barrack Retreat, embora existam outros estabelecimentos comerciais situados em outros pontos da cidade, que quase sempre é dominado pelos chineses.

Atualmente as lojas em sua maioria, já oferecem conforto a seus clientes, com ambientes mais agradáveis, mais organizados e com maior variedade de mercadorias. ${ }^{40}$ Para confirmar as mudanças que vem ocorrendo em Lethem, no que se refere às estruturas prediais, providenciamos algumas imagens de estabelecimentos antigos para que seja possível uma comparação com os atuais, como forma de evidenciar essas alterações. Nas imagens da figura 2, podemos observar tais mudanças:

\footnotetext{
${ }^{39}$ SIMÕES, Sulamita Oliveira. Dinâmicas das cidades-gêmeas da fronteira Guyana (Lethem) Brasil (Bonfim) e a questão aduaneira/tributária. 2014. 197f. Dissertação (Mestrado em Sociedade e Fronteiras) - Universidade Federal de Roraima, UFRR, Boa Vista, 2014, p. 129.

40 Para facilitar as vendas em Lethem, alguns estabelecimentos comerciais aceitam pagamento em moeda brasileira, o real, na moeda local, o dólar guianense e, ainda, aceitam cartão de crédito. Entretanto, os lojistas locais afirmam que é difícil encontrar o dólar guianense em circulação na cidade de Lethem, pois o que prevalece em circulação é a moeda brasileira. Em Lethem os produtos comercializados são bastante diversificados, vão desde artigos para decoração, perfumes importados, eletroeletrônicos, eletrodomésticos, móveis, utensílios para jardim, louças, brinquedos, maquiagem, bicicletas, confecção, roupas infantis, dentre outros.
} 
Figura 2 - Imagens dos estabelecimentos comerciais antigos e novos de Lethem (Gy).

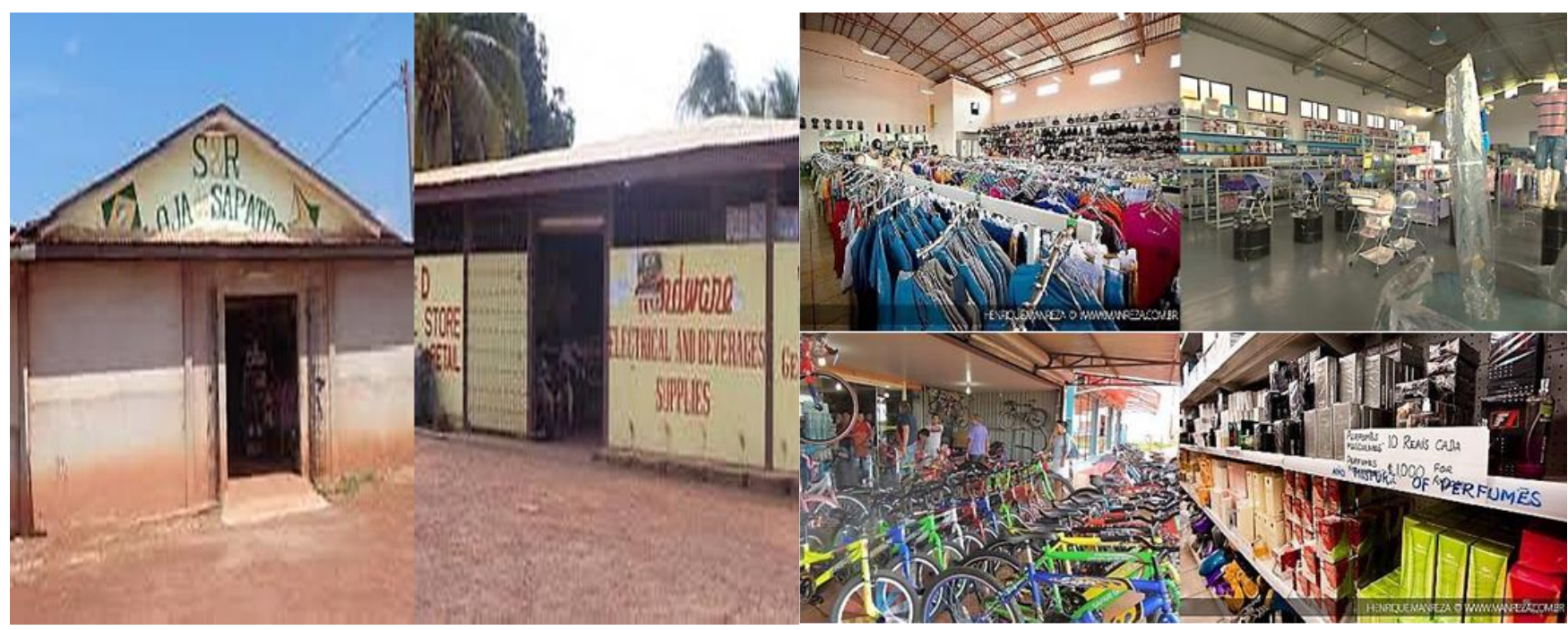

Fonte: Júlia Maria Corrêa Almeida. Pesquisa de Campo 2016.

Devido ao aumento da atividade comercial em Lethem nos últimos anos, tem-se oferecido maiores possibilidades de emprego. No entanto, observamos de forma unânime que esses trabalhadores migrantes desejam conseguir trabalho em sua própria cidade, ou seja, no município de Bonfim. Mas devido às poucas opções na cidade, eles acabam migrando em busca de emprego e melhores condições de vida.

\section{CONSIDERAÇÕES FINAIS}

As cidades fronteiriças de Bonfim e Lethem possuem uma dinâmica de "ir e vir" muitas vezes concebida pela lógica do comércio contemporâneo. Precisamente, os sujeitos, assim como o aprendizado proveniente das vivências experimentadas nesse contexto, são ignorados no processamento de políticas, sobretudo, no que se refere às possibilidades de desenvolvimento regional da fronteira do Brasil/Guiana.

Importante mencionar que esses trabalhadores transmigrantes, ao deixarem seu país em direção a outro, efetivam uma mobilidade diária e contínua que está sendo impulsionada pela contextura econômica. Essa condição da "mobilidade laboral" não surge como uma escolha, mas sim como uma 'exigência' do mundo capitalista e como meio de sobrevivência nessa região periférica da Amazônia.

Desse modo, é necessário estar alerta ainda assim ao entendimento, aliás, muito constante de que uma prática não possa se cumprir de maneira simultânea "espontâneoobrigatória", dito de outra forma, nessa região fronteiriça surgem interações que estão sendo instituídas como relutância das dinâmicas observadas nesse espaço geográfico - inacabadas e inconstantes -, em razão da coexistência desses acontecimentos e suas particularidades.

CANOA DO TEMPO - Mobilidade Humana e Trabalho: A situação de brasileiros em Lethem na Guiana 
Nessa cidade, não existem medidas que padronizem as condições laborais dos trabalhadores brasileiros, como também dos guianenses. Os brasileiros que trabalham em Lethem não possuem nenhum tipo de contrato formal de trabalho, que regulamente suas atividades, mais precisamente, ocorre apenas um controle de frequência, ou seja, uma espécie de 'combinado verbal' entre empregado e empregador, que torna essa relação de trabalho nessa transfronteira contraditória e complexa.

Nessa cidade, não existem medidas que padronizem as condições laborais dos trabalhadores brasileiros, como também dos guianenses. Os brasileiros que trabalham em Lethem não possuem nenhum tipo de contrato formal de trabalho, que regulamente suas atividades, mais precisamente, ocorre apenas um controle de frequência, ou seja, uma espécie de 'combinado verbal' entre empregado e empregador, que torna essa relação de trabalho nessa transfronteira contraditória e complexa.

Por meio de dados resultantes dessa pesquisa, é possível inferir que em Lethem, efetivamente, não se pratica nenhuma padronização salarial, ou seja, os estabelecimentos contratam, delegam as funções e estipulam os salários praticados nos estabelecimentos, de acordo com suas conveniências e necessidades, de forma aleatória, sem levar em consideração nenhuma norma reguladora local, se é que existe.

Questões como a super exploração do trabalho, deslocamento compulsório, processo de mundialização do capital, acumulação do capital, desemprego, flexibilização, desregulamentação, precarização enfim, mudanças nas relações e condições de trabalho carecem, portanto, de um enfrentamento por meio de estudos, pesquisas, discussões que tragam à tona essa realidade, como condição inerente a essa dinâmica presente nessa fronteira.

Em nosso estudo, não pretendemos esgotar, obviamente, o assunto da mobilidade humana e das questões do universo do trabalho que se instituem nessa região. Contudo, é indispensável considerar, que perante a relevância dessa temática tão atual, é imprescindível ampliar explicações e interpretações, tratar a matéria com a urgência que merece.

Recebido em: 05/03/2019

Aceito em: 21/09/2019 


\section{REFERÊNCIAS BIBLIOGRÁFICAS:}

ARAGÓN, Luís E. Aproximação ao estudo da migração internacional na Pan- Amazônia. In: ARAGÓN, L. E. (Org.). Migração Internacional na Pan-Amazônia. Belém: NAEA/UFPA, 2009.

BAENINGER, Rosana. Notas acerca das migrações internacionais no século 21. In: BAENINGER, R. (Org.). Migração Internacional. Campinas: Núcleo de Estudos de População - Nepo/Unicamp, 2013.

BAINES, Stephen G. A fronteira Guiana - Brasil e etnicidade entre povos indígenas. Revista Brasil do Caribe, Goiânia, v. VII, n.13, p.197-210, jul. 2006.

BECKER, Bertha K. Amazônia: Geopolítica na virada do III milênio. Rio de Janeiro: Garamond, 2007.

BRASIL. Lei no 11.918, de 9 de abril de 2009. Denomina Ponte Prefeito Olavo Brasil Filho, a ponte sobre o Rio Tacutu, na BR- 401, Km 120, no Município de Bonfim, no Estado de Roraima. Brasília, DF D.O.U., 13/04/2009. Disponível em: <http://presrepublica.jusbrasil.com.br/legislacao/230877/lei-11918-09>. Acesso em: 04 de mar. 2019.

CARDOZO, Maria José Pires Barros. A produção flexível e a formação do trabalhador: o modelo da competência e o discurso da empregabilidade. In: SOUSA, A. A.; ARRAIS NETO, E. A.; FELIZARDO, J. M.; CARDOZO, M. J. P.; BEZERRA, T. S. A. M. (Orgs.). Trabalho, capital mundial e formação dos trabalhadores. Fortaleza: Senac/Ceará; Edições UFC, 2008.

CATTANI, Antonio David. A vida precária: bases para a nova submissão. In: CATTANI, A. D.; DÍAZ, L. M (Orgs.). Desigualdades na América Latina: novas perspectivas analíticas. Traduzido por Ernani Ssó. Porto Alegre: Editora da UFRGS, 2005.

CHESNAIS, François. Mundialização do capital e jogo da lei da população inerente ao capitalismo. In: SOUSA, A. A.; ARRAIS NETO, E. A.; FELIZARDO, J. M. CARDOZO, M. J. P.; BEZERRA, T. S. A. M. (Orgs.). Trabalho, capital mundial e formação dos trabalhadores. Fortaleza: Editora Senac/Ceará; Edições UFC, 2008.

CORBIN, Hisakhana. Migração Internacional e desenvolvimento: O caso da Guiana. In: ARAGÓN, L. E. (Org.). Migração Internacional na Pan-Amazônia. Belém: NAEA/UFPA, 2009.

COSTA, Edmilson. A globalização e o capitalismo contemporâneo. $1^{\text {a }}$ Ed. São Paulo: Expressão Popular, 2008.

COSTA PINTO, L. A. A Transição e os seus Padrões. In: Desenvolvimento Econômico e Transição Social. $2^{a}$ ed. rev. Rio de Janeiro: Civilização brasileira, 1978. 
GAUDEMAR, Jean-Paul. Mobilidade do trabalho e acumulação de capital. Lisboa: Estampa, 1977.

GORENDER, Jacob. Globalização, tecnologia e relações de trabalho. Revista Estudos Avançados, USP, v.11, n.29, p.311-340, jan/abr. 1997.

HIRATA, Helena. Globalização e divisão sexual do trabalho. Cadernos Pagu, n.16- 17, p.139-156, 2001/02.

IBGE. Censo 2010. Disponível em: http://www.censo2010.ibge.gov.br. Acesso em 11 de março de 2018.

INSTITUTO BRASILEIRO DE GEOGRAFIA E ESTATÍSTICA - IBGE. 2010. Disponível em: <http://www.ibge.gov.br/home/>. Acesso em: 04 de mar. 2019.

JAKOB, Alberto Augusto Eichman. A migração internacional na Amazônia Legal brasileira e na metrópole de São Paulo nos anos 2000. In: BAENINGER, R. (Org.). Migração Internacional. Campinas: Núcleo de Estudos de População - Nepo/Unicamp, 2013.

MARX, Karl. Trabalho assalariado e capital e salário, preço e lucro. $1^{\text {a }}$ Ed. São Paulo: Expressão Popular, 2006.

MENESES, Antonio Vaz de. Cultura de fronteira Brasil/Guiana: festas. Boa Vista, 2014. 150 f. Dissertação (Mestrado em Sociedade e Fronteiras) - Universidade Federal de Roraima UFRR, 2014.

MÉSZÁROS, I. O poder da ideologia. São Paulo: Boitempo, 2004.

OIT - Organização Internacional do Trabalho. Declaração sobre justiça social para uma globalização equitativa. $\quad$ s.d.c. Disponível em: <http://www.oit.org.br/sites/default/files/topic/oit/doc/declaracao_oit_globalizacao_129.pdf>. Acesso em: 04 de mar. 2019.

OLIVEIRA, Márcia Maria de. Dinâmicas migratórias na Amazônia contemporânea. 2014. 340f. Tese (Doutorado em Sociedade e Cultura na Amazônia) - Universidade Federal do Amazonas, UFAM, Manaus, 2014.

OLIVEIRA, Roniel Vitor de; BETHONICO, Maria Barbosa de Magalhaes. Fatores históricos de ocupação e evolução demográfica do município de Bonfim - RR. In: ROSA FILHO, A.; BESERRA NETA, L. C. (Orgs.). Um olhar geográfico. Boa Vista: Editora da UFRR, 2013.

PEREIRA, Mariana C. A ponte imaginária: o trânsito de etnias na fronteira Brasil- Guiana. 2005. Tese (Doutorado em Antropologia Social) - Centro de Pesquisa e Pós-Graduação em Estudos Comparados sobre América Latina e Caribe (CEPPAC), Universidade de Brasília, Brasília, 2005.

POCHMANN, Márcio. Desempregados do Brasil. In: ANTUNES, R. (Org.). Riqueza e miséria do trabalho no Brasil. São Paulo: Editora Boitempo, 2006. 
SILVA FILHO. A Amazônia e o plano de integração nacional: os projetos de expansão e o avanço do capital nas sociedades tradicionais. Tempo Amazônico, v. V.3, p. 136-152, 2017.

SIMÕES, Sulamita Oliveira. Dinâmicas das cidades-gêmeas da fronteira Guyana (Lethem) Brasil (Bonfim) e a questão aduaneira/tributária. 2014. 197f. Dissertação (Mestrado em Sociedade e Fronteiras) - Universidade Federal de Roraima, UFRR, Boa Vista, 2014.

SKYSCRAPERCITY. Ponte Bonfim/Lethem (Brasil/Guiana Inglesa) - Com conversor de mão. SkyscraperCity, $2005 . \quad$ Disponível em: <http://www.skyscrapercity.com/showthread.php?t=864564> Acesso em: 04 mar. 2019.

SPRANDEL, Marcia Anita (Org.). Direito dos trabalhadores migrantes: convenções internacionais, protocolos adicionais e leis e decretos. Coleção documentos de bolso, $\mathrm{n}^{\circ} 03$. Manaus: UEA, 2007.

VICHICH, Nora Pérez. Las políticas migratorias regionales y los derechos de los trabajadores: perspectivas e desafios. In: PRADO, E. J. P.; COELHO, R. (Orgs.). Migrações e trabalho. Brasília: Ministério Público do Trabalho, 2015.

VISENTINI, Paulo Fagundes. Guiana e Suriname: uma outra América do Sul. Brasília. Fundação Alexandre Gusmão, 2007. 